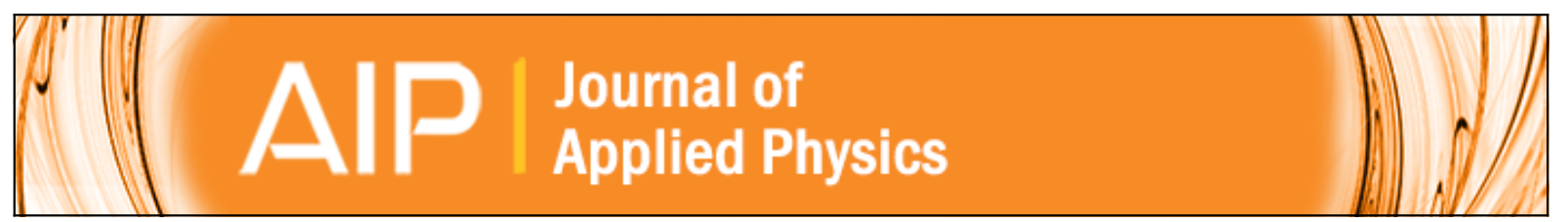

\title{
Probing on green long persistent Eu2+/Dy3+ doped Sr3SiAl4011 emerging phosphor for security applications
}

Bipin Kumar Gupta, Arun Kumar, Pawan Kumar, Jaya Dwivedi, G. N. Pandey, and Garima Kedawat

Citation: Journal of Applied Physics 117, 243104 (2015); doi: 10.1063/1.4922983

View online: http://dx.doi.org/10.1063/1.4922983

View Table of Contents: http://scitation.aip.org/content/aip/journal/jap/117/24?ver=pdfcov

Published by the AIP Publishing

\section{Articles you may be interested in}

Photoluminescence properties of SrAl 2 O 4 : Eu $2+$, Dy $3+$ thin phosphor films grown by pulsed laser deposition

J. Vac. Sci. Technol. A 28, 901 (2010); 10.1116/1.3299255

Near infrared long-persistent phosphorescence in SrAl 2 O 4 : Eu $2+$, Dy $3+, \operatorname{Er} 3+$ phosphors based on persistent energy transfer

Appl. Phys. Lett. 95, 231110 (2009); 10.1063/1.3272672

Recombination processes in undoped and rare-earth doped $\mathrm{M} \mathrm{Al} 2 \mathrm{O} 4(\mathrm{M}=\mathrm{Ca}, \mathrm{Sr}$ ) persistent phosphors investigated by optically detected magnetic resonance

Appl. Phys. Lett. 90, 051902 (2007); 10.1063/1.2437099

Low temperature fluorescence thermometer application of long afterglow phosphorescent Sr Al 12 O 19 : Eu $2+$ , Dy $3+$ crystals

Rev. Sci. Instrum. 76, 084901 (2005); 10.1063/1.1988147

Anomalous luminescence in $\mathrm{Sr} 4 \mathrm{Al} 14 \mathrm{O} 25$ : Eu, Dy phosphors

Appl. Phys. Lett. 81, 996 (2002); 10.1063/1.1490631

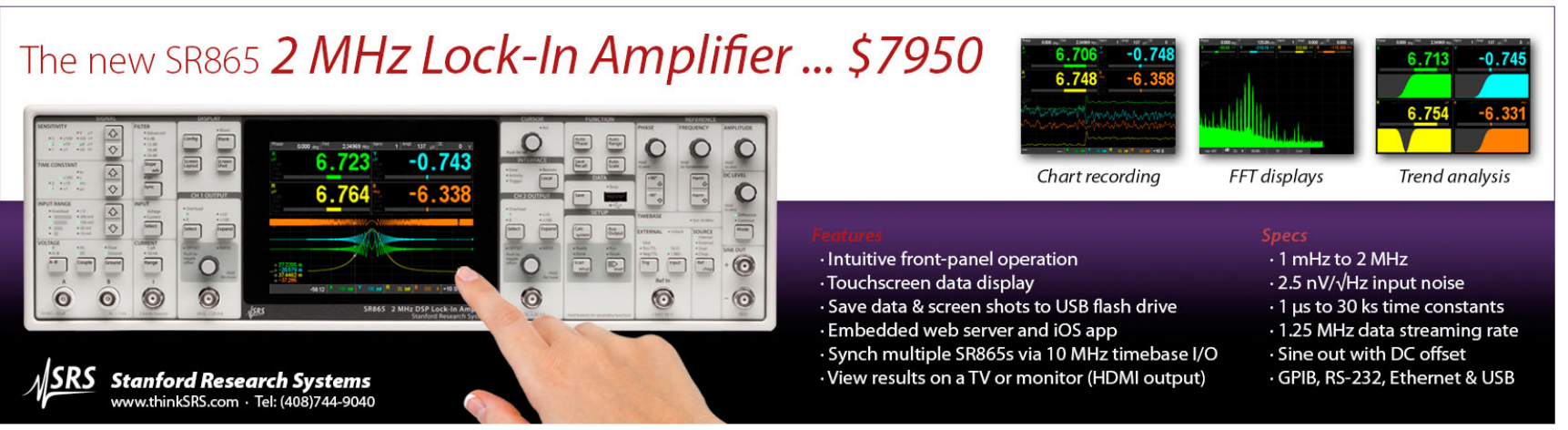




\title{
Probing on green long persistent $\mathrm{Eu}^{2+} / \mathrm{Dy}^{3+}$ doped $\mathrm{Sr}_{3} \mathrm{SiAl}_{4} \mathrm{O}_{11}$ emerging phosphor for security applications
}

\author{
Bipin Kumar Gupta, ${ }^{1, a)}$ Arun Kumar, ${ }^{1,2}$ Pawan Kumar, ${ }^{1,3}$ Jaya Dwivedi, ${ }^{1,3}$ G. N. Pandey, ${ }^{2}$ \\ and Garima Kedawat ${ }^{4}$ \\ ${ }^{1}$ CSIR—National Physical Laboratory, Dr K S Krishnan Road, New Delhi 110012, India \\ ${ }^{2}$ Amity Institute of Applied Science, Amity University, Noida, Uttar Pradesh 201303, India \\ ${ }^{3}$ Academy of Scientific and Innovative Research (AcSIR), CSIR-National Physical Laboratory campus, \\ New Delhi-110012, India \\ ${ }^{4}$ Department of Physics, Kalindi College, University of Delhi, New Delhi, 110008, India
}

(Received 7 January 2015; accepted 28 May 2015; published online 25 June 2015)

\begin{abstract}
Herein, a novel green emitting long-persistent $\mathrm{Sr}_{3} \mathrm{SiAl}_{4} \mathrm{O}_{11}: \mathrm{Eu}^{2+} / \mathrm{Dy}^{3+}$ phosphor was synthesized in a single phase form using facile solid state reaction method under the reducing atmosphere of $10 \% \mathrm{H}_{2}$ and $90 \% \mathrm{~N}_{2}$. The resulting phosphor exhibits hyper-sensitive strong broad green emission, peaking at $510 \mathrm{~nm}$ upon $340 \mathrm{~nm}$ excitation wavelength, which is attributed to the $4 \mathrm{f}^{6} 5 \mathrm{~d}^{1}-4 \mathrm{f}^{7}$ transitions of emission center of europium $\left(\mathrm{Eu}^{2+}\right)$ ions. Moreover, the incorporation of dysprosium $\left(\mathrm{Dy}^{3+}\right)$ ions, which act as effective hole trap centers with appropriate depth, largely enhances the photoluminescence characteristics and greatly improves the persistent intense luminescence behavior of $\mathrm{Sr}_{3} \mathrm{SiAl}_{4} \mathrm{O}_{11}: \mathrm{Eu}^{2+} / \mathrm{Dy}^{3+}$ phosphor under ultraviolet (UV) excitation. In addition, with the optimum doping concentration and sufficient UV excitation time period, the as-synthesized phosphor can be persisted afterglow for time duration $\sim 4 \mathrm{~h}$ with maximum luminescence intensity. Thus, these results suggest that this phosphor could be expected as an ultimate choice for next generation advanced luminescent materials in security applications such as latent finger-marks detection, photo-masking induced phosphorescent images, and security code detection. () 2015 AIP Publishing LLC. [http://dx.doi.org/10.1063/1.4922983]
\end{abstract}

\section{INTRODUCTION}

Long-persistent luminescence (LPL) is an important optical phenomenon, defined as the emission of visible light for longer hours after the ultraviolet (UV) excitation source is ceased off. This long persistent of light emission arises from the excitation of charge carriers (electrons and/or holes), which are trapped at certain defect sites and then de-trapped due to thermally stimulated recombination at room temperature ${ }^{1-3}$ The LPL phosphor materials are potentially applied in the fields such as optical data storage media, safety indications, graphic arts, interior decoration, radiation detection, and structural damage sensors. ${ }^{4-6}$ The photoluminescence (PL) properties of these phosphors have been extensively studied due to their high quantum efficiency in the visible region and good photochemical stability. ${ }^{7,8}$

Recently, $\mathrm{Eu}^{2+} / \mathrm{Dy}^{3+}$ co-doped alkaline-earth (Ba, Sr, $\mathrm{Ca}, \mathrm{Mg}$ ) aluminates host materials have attracted considerable attention as a new class of bright and long persistent luminescent phosphors for broad band emission area as well as these materials have been developed rapidly to replace the conventional sulfide afterglow materials. ${ }^{9-12}$ These rare earth doped strontium aluminates exhibit exceptional properties, such as higher luminescent intensity in visible region, higher quantum efficiency, longer lasting phosphorescence (or afterglow), excellent photo-resistant, and higher chemical stability. The long afterglow phosphor probe is associated

\footnotetext{
a) Author to whom correspondence should be addressed. Electronic mail: bipinbhu@yahoo.com.
}

with forensic, security signs, traffic signage, emergency route signs, and display applications. ${ }^{13-15}$ The $\mathrm{Eu}^{2+}$ ions doped phosphors provide typical emission bands from blue to red regions of the electromagnetic spectrum depending on the host lattice due to crystal-field effects. ${ }^{16}$ Moreover, the phosphorescence of dopant $\mathrm{Eu}^{2+}$ ion in host lattice is caused by the dipole allowed optical transition from the lowest $4 \mathrm{f}^{6} 5 \mathrm{~d}^{1}$ excited state to the $4 \mathrm{f}^{7} 5 \mathrm{~d}^{0}$ ground state. ${ }^{17}$ The afterglow time and intensity of these LPL phosphors materials can be enhanced by co-doping with other rare earth ion $\mathrm{Dy}^{3+}$. These $\mathrm{Eu}^{2+} / \mathrm{Dy}^{3+}$ co-doped strontium aluminates phosphors exhibit a rapid decay from the $\mathrm{Eu}^{2+}$ ion followed by a long persistent due to the $\mathrm{Dy}^{3+}$ ion, which trap the holes that are associated with the lattice defects in the host material. ${ }^{18}$ The peak position of emission spectrum depends on the nature of emitter, while the afterglow intensity and duration time are also associated with the property of the trap. Thus, these prevailing virtues make the $\mathrm{Eu}^{2+} / \mathrm{Dy}^{3+}$ co-doped alkaline-earth aluminates a promising contender that lead to a wide applications of the long persistent materials.

However, to the best of our knowledge, there is no literature available on the investigation regarding the green luminescence in $\mathrm{Eu}^{2+} / \mathrm{Dy}^{3+}$ doped strontium silicate aluminate $\left(\mathrm{Sr}_{3} \mathrm{SiAl}_{4} \mathrm{O}_{11}: \mathrm{Eu}^{2+} / \mathrm{Dy}^{3+}\right.$, hereafter labeled as $\left.\mathrm{E}_{0}\right)$ host lattice with long persistent phosphor for security applications till date. The substitution of $\mathrm{Si}$ in strontium silicate aluminate lattice is attributed to decreases in the band gap of host lattice, which make it more suitable for enhancement of the absorption spectrum in the visible range. The $\mathrm{E}_{0}$ phosphor powder could be used for the security applications such as latent finger-marks 
detection, photo-masking induced phosphorescent images, and security code detection. There are few reports on the potential of various phosphor materials for latent finger print detection application in forensic science. ${ }^{19-21}$ The solid state reaction method can be used for the fabrication of a variety of fluorescent color powders after the appropriate choice of proper host and dopant materials at economic cost.

In this paper, we have synthesized new composition of $\mathrm{E}_{0}$ phosphor using facile conventional solid state reaction method under the reducing atmosphere of hydrogen $\left(\mathrm{H}_{2}\right.$ : $10 \%)$ and nitrogen $\left(\mathrm{N}_{2}: 90 \%\right)$, which is merely reported in the literature. Moreover, this method provides high yields with purity, homogeneous products, cheap and reliable synthesis technique to prepare suitable phosphor material for security applications. This rare earth doped phosphor powder has an effect of offering strong phosphorescence emission efficiency in green region and an extended LPL effect. Thus, these results suggest that $\mathrm{E}_{0}$ material with long lasting afterglow properties represents a new and useful class of phosphor powder for many strategic applications. Further, we have successfully demonstrated the promising use of these as-synthesized luminescent phosphor based transparent solution on black paper in terms of latent finger-marks detection, photo-masking induced phosphorescent images, and security code detection on identity card.

\section{EXPERIMENT DETAILS}

\section{A. Synthesis of $\mathrm{Sr}_{2.90} \mathrm{SiAl}_{4} \mathrm{O}_{11}: \mathrm{Eu}_{\mathrm{x}}{ }^{2+} / \mathrm{Dy}_{0.10-\mathrm{x}}{ }^{3+}$ (where $x=0.01$ to 0.10 ) phosphor}

The LPL phosphor powder samples with nominal composition of $\mathrm{Sr}_{2.90} \mathrm{SiAl}_{4} \mathrm{O}_{11}: \mathrm{Eu}_{\mathrm{x}}{ }^{2+} / \mathrm{Dy}_{0.10-\mathrm{x}}{ }^{3+}$ (where $\mathrm{x}=0.01$ to 0.10 mol. \%, hereafter labeled as samples $\mathrm{E}_{1}, \mathrm{E}_{2}, \mathrm{E}_{3}, \mathrm{E}_{4}, \mathrm{E}_{5}$, $\mathrm{E}_{6}, \mathrm{E}_{7}, \mathrm{E}_{8}, \mathrm{E}_{9}$, and $\mathrm{E}_{10}$ ) were synthesized by conventional solid state reaction method. The powder sample name is also listed in Table I. Initially, powders of strontium carbonate $\left(\mathrm{SrCO}_{3}\right.$; Sigma Aldrich, 99.9\%), aluminium oxide $\left(\mathrm{Al}_{2} \mathrm{O}_{3}\right.$; Sigma Aldrich), silicon oxide $\left(\mathrm{SiO}_{2}\right.$; Sigma Aldrich), europium oxide $\left(\mathrm{Eu}_{2} \mathrm{O}_{3}\right.$; Sigma Aldrich, 99.9\%), and dysprosium oxide $\left(\mathrm{Dy}_{2} \mathrm{O}_{3}\right.$; Sigma Aldrich, $\left.99.9 \%\right)$ were used as starting materials. The schematic diagram of a MTI tubular furnace equipped with a microprocessor based temperature controller for the synthesis of $\mathrm{Sr}_{2.90} \mathrm{SiAl}_{4} \mathrm{O}_{11}: \mathrm{Eu}_{\mathrm{x}}{ }^{2+} / \mathrm{Dy}_{0.10-\mathrm{x}}{ }^{3+}$ (where

TABLE I. LPL phosphor powder samples with nominal composition of $\mathrm{Sr}_{2.90} \mathrm{SiAl}_{4} \mathrm{O}_{11}: \mathrm{Eu}_{\mathrm{x}}{ }^{2+} / \mathrm{Dy}_{0.10-\mathrm{x}}{ }^{3+}$.

\begin{tabular}{llc}
\hline \hline S. No. & $\mathrm{Sr}_{2.90} \mathrm{SiAl}_{4} \mathrm{O}_{11}: \mathrm{Eu}_{\mathrm{x}}{ }^{2+} / \mathrm{Dy}_{0.10-\mathrm{x}}{ }^{3+}$ & \\
\hline 1 & $\mathrm{x}=0.01$ to $0.10 \mathrm{~mol} \%)$ & Sample name \\
2 & $\mathrm{Sr}_{2.90} \mathrm{SiAl}_{4} \mathrm{O}_{11}: \mathrm{Eu}_{0.01}{ }^{2+} / \mathrm{Dy}_{0.09}{ }^{3+}$ & $\mathrm{E}_{1}$ \\
3 & $\mathrm{Sr}_{2.90} \mathrm{SiAl}_{4} \mathrm{O}_{11}: \mathrm{Eu}_{0.02}{ }^{2+} / \mathrm{Dy}_{0.08}{ }^{3+}$ & $\mathrm{E}_{2}$ \\
4 & $\mathrm{Sr}_{2.90} \mathrm{SiAl}_{4} \mathrm{O}_{11}: \mathrm{Eu}_{0.03}{ }^{2+} / \mathrm{Dy}_{0.07}{ }^{3+}$ & $\mathrm{E}_{3}$ \\
5 & $\mathrm{Sr}_{2.90} \mathrm{SiAl}_{4} \mathrm{O}_{11}: \mathrm{Eu}_{0.04}{ }^{2+} / \mathrm{Dy}_{0.06}{ }^{3+}$ & $\mathrm{E}_{4}$ \\
6 & $\mathrm{Sr}_{2.90} \mathrm{SiAl}_{4} \mathrm{O}_{11}: \mathrm{Eu}_{0.05}{ }^{2+} / \mathrm{Dy}_{0.05}{ }^{3+}$ & $\mathrm{E}_{5}$ \\
7 & $\mathrm{Sr}_{2.90} \mathrm{SiAl}_{4} \mathrm{O}_{11}: \mathrm{Eu}_{0.06}{ }^{2+} / \mathrm{Dy}_{0.04}{ }^{3+}$ & $\mathrm{E}_{6}$ \\
8 & $\mathrm{Sr}_{2.90} \mathrm{SiAl}_{4} \mathrm{O}_{11}: \mathrm{Eu}_{0.07}{ }^{2+} / \mathrm{Dy}_{0.03}{ }^{3+}$ & $\mathrm{E}_{7}$ \\
9 & $\mathrm{Sr}_{2.90} \mathrm{SiAl}_{4} \mathrm{O}_{11}: \mathrm{Eu}_{0.08}{ }^{2+} / \mathrm{Dy}_{0.02}{ }^{3+}$ & $\mathrm{E}_{8}$ \\
10 & $\mathrm{Sr}_{2.90} \mathrm{SiAl}_{4} \mathrm{O}_{11}: \mathrm{Eu}_{0.09}{ }^{2+} / \mathrm{Dy}_{0.01}{ }^{3+}$ & $\mathrm{E}_{9}$ \\
\hline \hline
\end{tabular}

$\mathrm{x}=0.01$ to $0.10 \mathrm{~mol} . \%$ ) phosphors is shown in Scheme 1 (see supplementary material). ${ }^{32}$ Stoichiometric molar ratios (2.90:1:4:0.03:0.07 for Sr:Si:Al:Eu:Dy) of raw materials were mixed thoroughly homogenized using a wet grinding method in a mortar-pestle (ethanol was used as the dispersing liquid). The obtained product was put in alumina crucible and sintered in furnace at a slow rate of $5^{\circ} \mathrm{C} / \mathrm{min}$ to $1300{ }^{\circ} \mathrm{C}$ for $3 \mathrm{~h}$ in the presence of reducing atmosphere of $10 \% \mathrm{H}_{2}$ and $90 \% \mathrm{~N}_{2}$. After cooling, the white colored product was obtained in the form of powder that was grinded gauzily. The yield of material was $>80 \%$ with a high degree of homogeneity. The various concentrations of $\mathrm{Eu}^{2+}$ and $\mathrm{Dy}^{3+}$ were substituted in $\mathrm{Sr}_{2.90} \mathrm{SiAl}_{4} \mathrm{O}_{11}: \mathrm{Eu}_{\mathrm{x}}{ }^{2+} / \mathrm{Dy}_{0.10-\mathrm{x}}{ }^{3+} \quad(\mathrm{x}=0.01$ to $0.10 \mathrm{~mol} . \%)$ host lattice. The optimized sample has shown a better photoluminescence intensity as compared to the different concentration of Eu and Dy substitution in place of Sr. The optimum concentration was found to be $\mathrm{x}=0.03$, for $\mathrm{E}_{3}$ phosphor sample, which is further explained in PL section. The protocol for synthesis of bulk $\mathrm{Sr}_{2.90} \mathrm{SiAl}_{4} \mathrm{O}_{11}: \mathrm{Eu}_{\mathrm{x}}{ }^{2+} / \mathrm{Dy}_{0.10-\mathrm{x}}{ }^{3+}$ (where $\mathrm{x}=0.01$ to $0.10 \mathrm{~mol}$ \%) long decay phosphor by conventional solid state reaction method is given in Scheme S2 (see supplementary material). ${ }^{32}$

\section{B. Detection of latent finger-marks and photo-masking induced phosphorescent images and security codes}

We have carried out practical applications, which are very significant for the security and investigation purposes. For obtaining the latent finger-marks detection, the as-synthesized $\mathrm{E}_{3}$ phosphor powder sample in white color was mixed thoroughly with the commercially available PVC gold medium (composition: polyvinyl chloride resin + cyclo hexanone + nitrobenzene + ethyl cellulose $+\mathrm{C}_{9}$ reducer), which is used in screen printing. ${ }^{22}$ The ratio of the white colored phosphor powder with the PVC gold medium was kept as $500 \mathrm{mg} / 20 \mathrm{ml}$. Then, the suspension was ultrasonicated for about $30 \mathrm{~min}$ at $25 \mathrm{kHz}$. The transparent $(\sim 67 \%)$ colloidal solution was obtained and the transmittance spectrum is shown in Fig. S1 (details given in supplementary material). ${ }^{32}$ A thick black paper surface was selected for finger-marks detection experiment. The application of the as-synthesized phosphor powder as finger-marks detection was carried out using a squirrel hair brush. All the fingermarks were obtained from the same donor and pressed onto the surface of the black paper. The finger-marks were taken from a donor of age $22 \mathrm{yr}$ and having good secretions. Then, the thick white colored phosphorescent mixture was thoroughly spread out using the standard spray nozzle (tip diameter $1 \mathrm{~mm}$ ) under Ar gas pressure. All samples were kept at room temperature. The developed finger-marks were excited under $365 \mathrm{~nm}$ UV lamp for $2 \mathrm{~min}$. The developed fingermarks were then afterglow for $\sim 4 \mathrm{~h}$ after the excitation source was ceased off. The phosphorescent images were recorded by using green sensitive Nikon high-resolution camera. Finally, these obtained phosphorescent finger-marks on black paper can work for investigation purposes. Additionally, the as-synthesized $\mathrm{E}_{3}$ phosphor was also used to carry out security application as in photo-masking induced phosphorescent images and security code detection on the 
basis of above experiment. Moreover, it can be also used in some other potential applications such as emergency signs, buildings and highways, plasma display panels, light-emitting diodes (LEDs), textile and luminous paints, etc.

\section{Characterizations}

The experiments were carried out in a MTI tubular furnace equipped with a microprocessor based temperature controller with an accuracy of $\pm 1{ }^{\circ} \mathrm{C}$. The as-synthesized $\mathrm{Sr}_{2.90}$ $\mathrm{SiAl}_{4} \mathrm{O}_{11}: \mathrm{Eu}_{\mathrm{x}}{ }^{2+} / \mathrm{Dy}_{0.10-\mathrm{x}}{ }^{3+}$ (where $\mathrm{x}=0.01$ to $0.10 \mathrm{~mol} . \%$ ) phosphor was thoroughly characterized using a number of different techniques. The XRD (X-ray diffraction; Rigaku: MiniFlex, $\mathrm{Cu}-\mathrm{K} \alpha_{1} ; \lambda=1.5406 \AA$ ) technique was performed for phase purity identification and gross structural analysis using the principle of Bragg-Brentano geometry ranging from $10^{\circ}$ to $80^{\circ}$ at a scanning rate of $2^{\circ} \mathrm{min}^{-1}$. Prior to the XRD measurement, calibration of the diffractometer was achieved with silicon powder $\left(\mathrm{d}_{111}=3.1353 \AA\right){ }^{23}$ The as-synthesized sample is merely reported; therefore, we have used the nearly well matched JCPDS card (JCPDS, File No. 24-1187) to index the planes of $\mathrm{E}_{3}$ phosphor. Scanning electron microscopy (SEM) observations were obtained using a Carl ZEISS EVOR-18 instrument at $10 \mathrm{kV}$ operating voltage. The microstructural characterizations were carried out by high-resolution transmission electron micrographs (HRTEM) and transmission electron micrographs (TEM) (Technai, Model No. G20-twin, $200 \mathrm{kV}$ with super-twin lenses having point and line resolutions of 0.144 and $0.232 \mathrm{~nm}$, respectively). Fourier transform infrared (FTIR) spectroscopic measurements were performed on a Thermo Scientific FTIR spectrometer (model: NICOLET 6700). Raman spectra were obtained using Renishaw InVia Raman spectrometer, UK with an excitation source of $514.5 \mathrm{~nm}$. The XPS analysis was carried out in an ultra-high vacuum (UHV) chamber equipped with a hemispherical electron energy analyzer (Perkin Elmer, PHI1257) using non-monochromatized $\mathrm{Al} \mathrm{K} \alpha$ source (excitation energy of
$1486.7 \mathrm{eV}$ ) with a base pressure of $4 \times 10^{-10}$ Torr at room temperature. XPS spectrum corresponds a binding energy survey scan, which was recorded with pass energy of $100 \mathrm{eV}$. UV-Vis absorption spectra were recorded on a Shimadzu UV-Vis-NIR spectrophotometer (UV-3600). The PL characterization was done using PL spectrometer (Edinburgh FLSP920) with a xenon lamp as an excitation source. The time resolved PL (TRPL) decay curves were recorded using kinetics decay measurements with the PL spectrometer (Edinburgh FLSP-920). Color measurement was done by the spectrophotometric method using the spectral energy distribution of the given sample and then calculating the color coordinates $\mathrm{x}$ and y. The phosphor sample was irradiated using $450 \mathrm{~W}$ xenon lamp for $45 \mathrm{~min}$, prior to the afterglow measurements. All the measurements were carried out at room temperature.

\section{RESULTS AND DISCUSSION}

Fig. 1(a) shows the typical optical photographs of as-synthesized $\mathrm{E}_{3}$ phosphor under room light as well as $365 \mathrm{~nm}$ UV lamp (a strong green emission afterglow is noticeable under UV excitation due to the $\mathrm{Eu}^{2+}$ and $\mathrm{Dy}^{3+}$ ions). The as-synthesized long decay $\mathrm{Sr}_{2.90} \mathrm{SiAl}_{4} \mathrm{O}_{11}: \mathrm{Eu}_{\mathrm{x}}{ }^{2+} /$ $\mathrm{Dy}_{0.10-\mathrm{x}}{ }^{3+}(\mathrm{x}=0.01$ to $0.10 \mathrm{~mol} \%)$ phosphor powder was obtained in white color. The PL properties are greatly influenced by phase purity, crystallite size, and crystallinity of as-synthesized LPL phosphor samples. The structural purities of $\mathrm{Sr}_{2.90} \mathrm{SiAl}_{4} \mathrm{O}_{11}: \mathrm{Eu}_{\mathrm{x}}{ }^{2+} / \mathrm{Dy}_{0.10-\mathrm{x}}{ }^{3+}$ ( $\mathrm{x}=0.01$ to $0.10 \mathrm{~mol}$. \%) phosphor samples were studied by the powder XRD. Fig. 1(b) shows XRD pattern of $E_{3}$ phosphor sample. In order to index the low intensity XRD peaks, the space group and unit cell parameters of the $\mathrm{E}_{3}$ phosphor by Le Bail fitting of the XRD data using the "FULLPROF" refinement program have been determined. The peak profiles were defined by Pseudo-Voigt function, and the background was described in terms of a six coefficient polynomial. A very good fitting is observed by considering the $P a^{3}$ space group (cubic-type

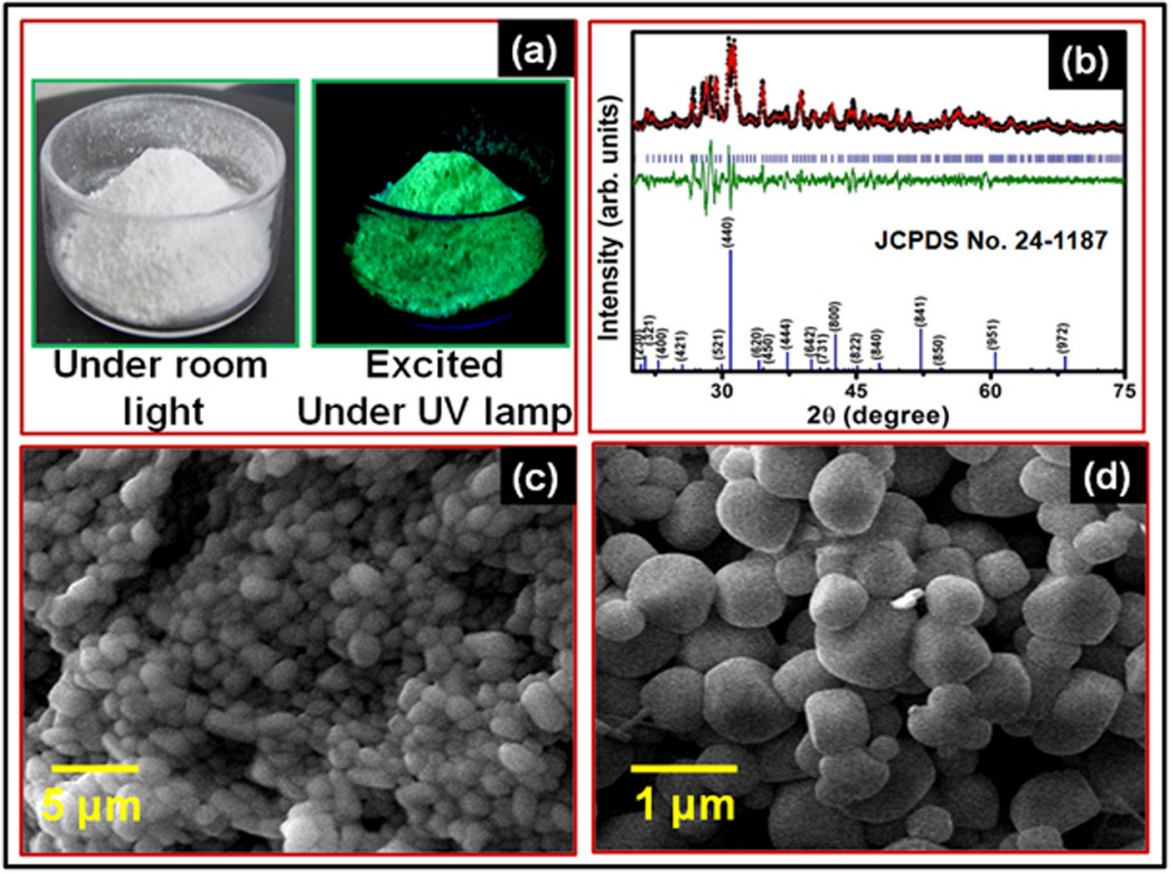

FIG. 1. (a) Typical photographs of assynthesized $\mathrm{E}_{3}$ phosphor under room light as well as $365 \mathrm{~nm}$ UV lamp; a long persist strong green emission appears due to combination of $\mathrm{Eu}^{2+}$ and $\mathrm{Dy}^{3+}$ trap level, (b) XRD of $\mathrm{E}_{3}$ phosphor; observed (black dots), calculated (continuous red line), and difference (bottom green line) profiles obtained after Le Bail fit for $\mathrm{E}_{3}$ phosphor using $\mathrm{Pa}^{3}$ space group (cubictype crystal structure), vertical tick marks above the difference plot show the positions of the Bragg peaks and corresponding JCPDS No. 24-1187 database standard for $E_{3}$ phosphor (bottom blue lines), (c) SEM image and (d) magnified view of Fig. 1(c) of $\mathrm{E}_{3}$ phosphor. 
crystal structure). No diffraction peaks associated with impurity ions were detected. The lattice parameters were estimated from experimentally observed $\mathrm{d}$ values and indexed (hkl) plane through a computer program based least square fitting method using "unit cell refinement software." ${ }^{24-28}$ The estimated lattice parameters $\mathrm{a}=\mathrm{b}=\mathrm{c}=(15.868 \pm 0.0018) \AA$ are comparable to the standard lattice parameters $\mathrm{a}=\mathrm{b}=\mathrm{c}$ $=15.844 \AA$ (JCPDS, File No. 24-1187). The estimated unit cell parameters and cell volume for variants of $\mathrm{Sr}_{2.90}$ $\mathrm{SiAl}_{4} \mathrm{O}_{11}: \mathrm{Eu}_{\mathrm{x}}{ }^{2+} / \mathrm{Dy}_{0.10-\mathrm{x}}{ }^{3+}$ phosphor in the range of $\mathrm{x}=0.01$ to $0.10 \mathrm{~mol} . \%$ are given in Table SI (details given in supplementary material). ${ }^{32}$ The co-ordination number of $\mathrm{Eu}_{\mathrm{x}}{ }^{2+} / \mathrm{Dy}_{0.10-\mathrm{x}}{ }^{3+}$ is four per unit cell of cubic lattice of $\mathrm{Sr}_{2.90} \mathrm{SiAl}_{4} \mathrm{O}_{11}: \mathrm{Eu}_{\mathrm{x}}{ }^{2+}$ $/ \mathrm{Dy}_{0.10-\mathrm{x}}{ }^{3+}$ phosphor as per their Wyckoff positions in space group of $\mathrm{Pa}^{3}$. It can be noticed that the cell parameters and cell volume increase with increase in the concentration ratio of activator/co-activators ions $\mathrm{Eu}_{\mathrm{x}}{ }^{2+} / \mathrm{Dy}_{0.10-\mathrm{x}}{ }^{3+}$ up to $0.03(\mathrm{x}=0.03)$ and decrease thereafter. ${ }^{29}$ Such characteristics have been previously observed and discussed for other rare-earth oxide systems in our earlier publications. ${ }^{24-28}$ This is occur due to the presence of access amount of activators/co-activators in host lattice, which creates lattice contraction effect. As a result, photoluminescence intensity also decreases. ${ }^{24-28}$ More details about the effect of higher concentration of activator/co-activators have been discussed in photoluminescence section. The particle size of the sample can be estimated using Scherer's formula, it is $\sim 800 \mathrm{~nm}$. Further, the crystallinity of $\mathrm{E}_{3}$ phosphor is also confirmed by Raman spectrum ranging from 100 to $1000 \mathrm{~cm}^{-1}$ using $514.5 \mathrm{~nm}$ wavelength, as shown in Fig. S2 (details given in supplementary material). ${ }^{32}$ It reveals that the Raman peaks at 118, 144, 238, 340, 373, 402, 468, 515, 538, 843,868 , and $953 \mathrm{~cm}^{-1}$ correspond to the cubic phase of phosphor, which are consistent with the XRD results. Basically, these peaks are associated with bond of $\mathrm{Al}-\mathrm{O}, \mathrm{AlO}_{4}^{-}, \mathrm{Sr}-0, \mathrm{Al}-\mathrm{Si}, \mathrm{Si}-$ $\mathrm{O}$, and $\mathrm{Sr}-\mathrm{Si}$, which have structural bonding for $\mathrm{Sr}_{3} \mathrm{SiAl}_{4} \mathrm{O}_{11}$ host lattice. Furthermore, we also employed the FTIR to ensure the quality of $\mathrm{Sr}_{2.90} \mathrm{SiAl}_{4} \mathrm{O}_{11}: \mathrm{Eu}_{\mathrm{x}}{ }^{2+} / \mathrm{Dy}_{0.10-\mathrm{x}}{ }^{3+} \quad(\mathrm{x}=0.01$ to 0.10 mol. \%) phosphor samples. The FTIR absorbance spectrum of $E_{3}$ phosphor sample in the range of $750-3750 \mathrm{~cm}^{-1}$ is shown in Fig. S3 (details given in supplementary material). ${ }^{32}$ The surface morphology has been examined by SEM technique. The SEM images of $E_{3}$ phosphor sample and its magnified view are shown in Figs. 1(c) and 1(d), respectively. The obtained oval fine shape structures are in solid form having average particle size $\sim 800 \mathrm{~nm}$. The PL intensity of phosphorescent material is also affected by particle surface morphology and it becomes higher for spherical particles compared to irregular-shaped morphology of particles.

In order to study the microstructural information of as-synthesized phosphor, we performed TEM/HRTEM microscopic analysis. Figs. 2(a) and 2(b) show the TEM images of $\mathrm{E}_{3}$ phosphor sample and its large view, respectively. The obtained TEM micrograph (Fig. 2(a)) clearly demonstrates that the obtained microstructures are composed of agglomerated particles with oval shaped structure having average particle size of $\sim 800 \mathrm{~nm}$ (Fig. 2(b)). A typical HRTEM image of $E_{3}$ phosphor sample is shown in Fig. 2(c). The precise observation of the HRTEM image indicates that the sample exhibits lattice fringes with an estimated

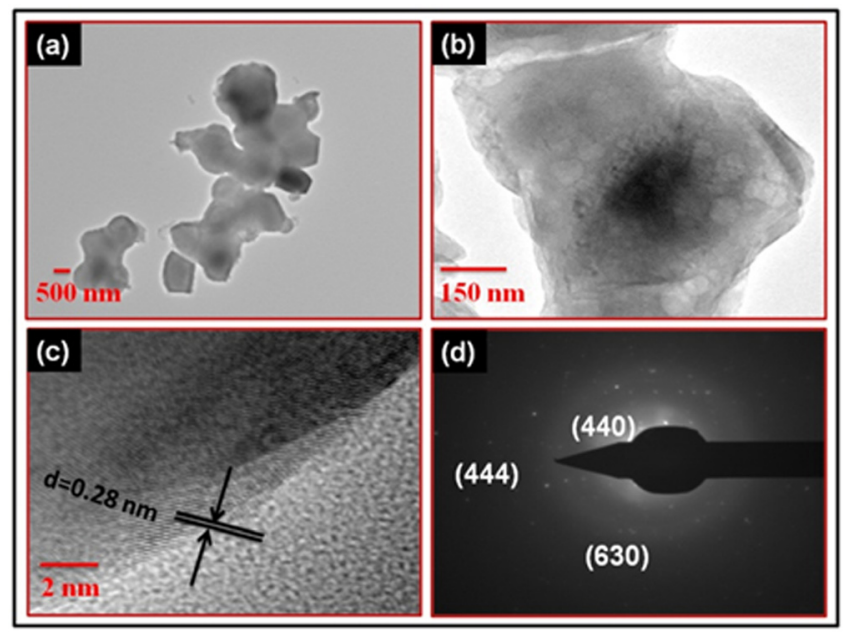

FIG. 2. (a) TEM image, (b) magnified view of Fig. 2(a) of $E_{3}$ phosphor, (c) HRTEM image showing the $\mathrm{d}$ spacing of $\mathrm{E}_{3}$ phosphor $\approx 0.28 \mathrm{~nm}$, which corresponds to the (440) plane, and (d) SAED pattern of $E_{3}$ phosphor.

interspacing of $\sim 0.28 \mathrm{~nm}$, corresponding to the (440) plane of phosphor with a cubic phase, which have good consistency with the obtained XRD results. Fig. 2(d) represents the selected area electron diffraction (SAED) pattern of $E_{3}$ phosphor sample, which clearly reveals the high quality phosphor with (440), (444), and (630) index planes. XPS is a powerful spectroscopic technique for the characterization of surfaces with chemical bonding. The XPS spectrum is shown in Fig. S4 (details given in supplementary material). ${ }^{32}$ The XPS spectra confirm the presence of $\mathrm{Sr}, \mathrm{Si}, \mathrm{Al}, \mathrm{Eu}, \mathrm{Dy}$, and $\mathrm{O}$ elements in $\mathrm{E}_{3}$ phosphor. It can be noticed that the Eu and Dy atoms existed as di- and tri-valent states in the assynthesized powder. It is apparent from the intensity that the contribution of Dy element is more than that of Eu element, thereby justifying the stoichiometry of the as-synthesized $E_{3}$ phosphor.

The UV-vis absorption spectra of undoped $\mathrm{Sr}_{4} \mathrm{Al}_{4} \mathrm{O}_{11}$ and $\mathrm{Sr}_{3} \mathrm{SiAl}_{4} \mathrm{O}_{11}$ are shown in Fig. 3(a). The optical band gap was calculated using Tauc relation. The variations of band gap occur on doping of $\mathrm{Si}$ in $\mathrm{Sr}_{4} \mathrm{Al}_{4} \mathrm{O}_{11}$ phosphor. A graph was plotted between $(\alpha \mathrm{h} \nu)^{2}$ with $\mathrm{h} \nu$, as shown in Fig. 3(b). The energy band gap can be determined by extrapolating straight line portion of curve to the intercept of the photon energy axes. The energy band gap decreased from $4.94 \mathrm{eV}$ to $4.83 \mathrm{eV}$. The substitution of $\mathrm{Si}$ in strontium silicate aluminate lattice is attributed to decreases in the band gap of host lattice, which make it more suitable for enhancement of the absorption spectrum in the visible range. For the optimization of concentration of $\mathrm{Eu}^{2+} / \mathrm{Dy}^{3+}$, the PL excitation and emission spectra for $\mathrm{Sr}_{2.90} \mathrm{SiAl}_{4} \mathrm{O}_{11}: \mathrm{Eu}_{\mathrm{x}}{ }^{2+}$ / $\mathrm{Dy}_{0.10-\mathrm{x}}{ }^{3+}$ (from $\mathrm{x}=0.01$ to $0.10 \mathrm{~mol} . \%$ ) phosphors corresponding to the different concentration of $\mathrm{Eu}^{2+}$ and $\mathrm{Dy}^{3+}$ ions are shown in Figs. S5 and S6 (details given in supplementary material), ${ }^{32}$ respectively. The PL spectra demonstrate that the peak position and shape of the emission spectra are identical for all samples. These spectra show one broad band from 450 to $600 \mathrm{~nm}$ with a shoulder peak at about $510 \mathrm{~nm}$ wavelength and exhibit an emission in the green region due to the crystal field splitting of the $\mathrm{Eu}^{2+} \mathrm{d}$-orbital. 

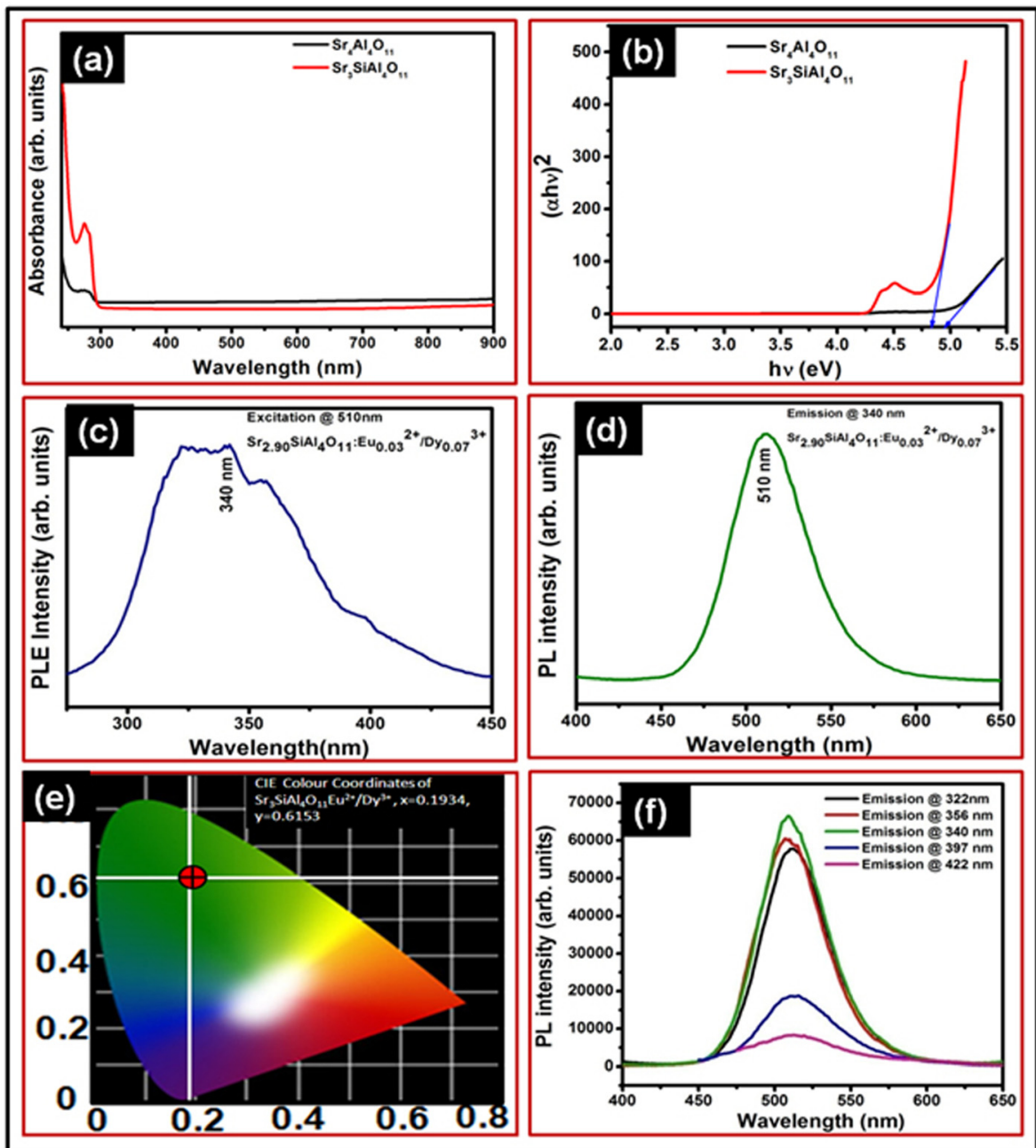

FIG. 3. (a) Absorption spectra of undoped $\mathrm{Sr}_{4} \mathrm{Al}_{4} \mathrm{O}_{11}$ and $\mathrm{Sr}_{3} \mathrm{SiAl}_{4} \mathrm{O}_{11}$ phosphor and (b) plot of $(\alpha \mathrm{h} \nu)^{2}$ versus $\mathrm{h} \nu$ for determination of band gap of undoped $\mathrm{Sr}_{4} \mathrm{Al}_{4} \mathrm{O}_{11}$ and $\mathrm{Sr}_{3} \mathrm{SiAl}_{4} \mathrm{O}_{11}$, (c) PL excitation spectrum of $\mathrm{E}_{3}$ phosphor recorded at $510 \mathrm{~nm}$ emission showing a excitation wavelength at $340 \mathrm{~nm}$, (d) PL emission spectrum of $\mathrm{E}_{3}$ phosphor recorded at $340 \mathrm{~nm}$ excitation exhibiting a hyper-intense green emission at $510 \mathrm{~nm}\left(4 \mathrm{f}^{6} 5 \mathrm{~d}^{1}-4 \mathrm{f}^{7}\right.$ transition) at room temperature, (e) color coordinate of green emission; $\mathrm{x}=0.1934$ and $\mathrm{y}=0.6153$, and (f) PL spectra at different excitation wavelengths $\left(\lambda_{\mathrm{ex}}=322,340,356,397\right.$, and $422 \mathrm{~nm})$ of $E_{3}$ phosphor show maximum green emission at $340 \mathrm{~nm}$ excitation wavelength.
This is a strong indication that the $\mathrm{Eu}$ ion is in a divalent $\left(\mathrm{Eu}^{2+}\right.$, green emission) rather than trivalent $\left(\mathrm{Eu}^{3+}\right.$, red emission) state. Moreover, the intensity of PL emission increases with respect to the concentration of $\mathrm{Eu}^{2+}$ ions, varying from $\mathrm{x}=0.01$ to $\mathrm{x}=0.03$ and after that, the PL intensity sharply decreases due to the quenching phenomena at higher concentration of dopant ions $\left(\mathrm{Eu}^{2+}\right.$ and co-dopant $\left.\mathrm{Dy}^{3+}\right)$. It is well known that the ratio of Eu/Dy doping concentration affects the distance between the Eu-Eu, Eu-Dy, and Dy-Dy ions in the host lattice ( $E_{3}$ sample). When the doping concentration ratio of $\mathrm{Eu} / \mathrm{Dy}\left(\mathrm{Sr}_{2.90} \mathrm{SiAl}_{4} \mathrm{O}_{11}: \mathrm{Eu}_{\mathrm{x}}{ }^{2+} / \mathrm{Dy}_{0.10-\mathrm{x}}{ }^{3+}, \mathrm{x} \leq 0.03\right)$ and the distance between the two Eu-Eu, Eu-Dy, and Dy-Dy ions are large, every one of the these ions can be regarded as an isolated luminescent centres and co-centers, which independently emits light without any interference. As a result, the PL intensity of $\mathrm{Sr}_{2.90} \mathrm{SiAl}_{4} \mathrm{O}_{11}: \mathrm{Eu}_{\mathrm{x}}{ }^{2+} / \mathrm{Dy}_{0.10-\mathrm{x}}{ }^{3+}$ phosphor increases up to $\mathrm{x}=0.03$. On the other hand, higher doping concentration of Eu/Dy beyond 0.03 mol. \% ( $x>0.03)$ and the ratio of the $\mathrm{Eu} / \mathrm{Dy}$ ions can mutually interact by an electric multi-polar process due to the shortened distances between the two Eu-Eu, Eu-Dy, and Dy-Dy ions. In the latter case, the energy transfer rates of Eu/Dy ions easily exceed the radiative rates. Thus, the absorbed photon energy rapidly migrates among Eu/Dy ions in the host lattice, which can decrease the probabilities of the radiative transitions of $\mathrm{Eu} / \mathrm{Dy}$ ions, and even quench the fluorescence, if the excited state gets trapped in an energy sink with a high non-radiative deactivation rate constant. This is recognized as a concentration quenching of phosphorescence. ${ }^{27,30}$ The maximum PL intensity peak is obtained at $510 \mathrm{~nm}$ wavelength for $\mathrm{E}_{3}$ phosphor sample. Thus, $x=0.03$ is the optimized concentration to obtain the high intense luminescence phosphor material.

The PL excitation spectrum of $\mathrm{E}_{3}$ phosphor was recorded by monitoring at $510 \mathrm{~nm}$ fixed wavelength, as shown in Fig. 3(c). This spectrum consists of a wide band peaking at $340 \mathrm{~nm}$, corresponding to the crystal field components of the $5 \mathrm{~d}$ level in the excited $4 \mathrm{f}^{6} 5 \mathrm{~d}^{1}$ configuration of the $\mathrm{Eu}^{2+}$ ions. This strong excitation band of the host lattice in the UV range confirms the energy transfer from the host to the $\mathrm{Eu}^{2+}$ ions, which can acquire energy from the host. The $4 \mathrm{f}-5 \mathrm{~d}$ intra-transitions of $\mathrm{Eu}^{2+}$ occur, when excited by the UV light source. Thus, it illustrates the existence of $\mathrm{Eu}^{2+}$ ions and its role as an emission centers. This signifies that the as-synthesized phosphor can be energized by variety of illumination sources, especially, by most common natural sun light. The PL emission spectrum of $\mathrm{E}_{3}$ phosphor under $340 \mathrm{~nm}$ fixed excitation wavelength is displayed in Fig. 3(d). This spectrum reveals only one symmetric broad band intense green emission peaking at $510 \mathrm{~nm}$, which can be ascribed to the parity-allowed electronic $4 \mathrm{f}^{6} 5 \mathrm{~d}^{1} \rightarrow 4 \mathrm{f}^{7}$ transition of $\mathrm{Eu}^{2+}$ ions, which is affected by the host lattice. Any emission peaks of $\mathrm{Eu}^{3+}$ are 
not obtained in the emission spectra, resulting that $\mathrm{Eu}^{3+}$ ion in the samples has been completely reduced to $\mathrm{Eu}^{2+}$ ions. In as-synthesized phosphor, $\mathrm{Eu}^{2+}$ ions are the luminescent centers and the photo-excited luminescence is considered to be due to transition from the $5 \mathrm{~d}$ level to the $4 \mathrm{f}$ level of $\mathrm{Eu}^{2+}$ and holes in the traps are responsible for the long afterglow. The relative intensity between the strontium silicate aluminate host broad band and $4 \mathrm{f}^{6} 5 \mathrm{~d}^{1} \rightarrow 4 \mathrm{f}^{7}$ transition in Eu ${ }^{2+}$ strongly depends on the activation/deactivation of the host-to-electron-to-trapping centre and therefore energy-transfer processes allow the fine-tuning of the host emission chromaticity across the Commission Internationale d'Eclairage (CIE) diagram. The phosphorescence chromaticity coordinates of samples are calculated from the phosphorescence spectrum using chromaticity coordinate calculation method based on the CIE system. The CIE color coordinates obtained from emission spectra of $E_{3}$ phosphor are $\mathrm{x}=0.1934$ and $\mathrm{y}=0.6153$, as shown in Fig. 3(e) (chromaticity diagram). It is located typically in the green region. This emission-color fine tuning along the CIE chromaticity diagram can be also modulated by chemical factors $\left(\mathrm{Eu}^{2+}, \mathrm{Dy}^{3+}\right.$ concentration, nature of the electron and holes) and physical parameters (excitation wavelength and temperature). In order to explain the PL stability of synthesized phosphors, we also performed PL kinetic experiment at fixed $340 \mathrm{~nm}$ excitation wavelength. The obtained result reveals that the as-synthesized $\mathrm{E}_{3}$ exhibits good photon stability, as shown in Fig. S7 (details given in supplementary material). ${ }^{32}$ Fig. 3(f) depicts the other emission spectra at $322,340,356,397$, and $422 \mathrm{~nm}$ excitation wavelengths, which are all essentially the same differing only in their intensity. It attributes an emission at $510 \mathrm{~nm}$ wavelength and maximum intensity is obtained for $340 \mathrm{~nm}$ excitation wavelength.

The TRPL decay profile of the phosphor was recorded with the help of time correlated single photon counting technique for the $510 \mathrm{~nm}$ emission of $\mathrm{Eu}^{2+}$ excited at $340 \mathrm{~nm} \mathrm{UV}$ radiation by microsecond xenon flash lamp. The TRPL decay curve and exponentially fitting curves with attenuation data parameter of $E_{3}$ phosphor are shown in Figs. 4(a) and 4(b). The Y-axis of decay curve is in log scale. The large view of decay for half an hour is shown in inset of Fig. 4(a). The kinetic emission intensity of a sample over some time (half an hour) has almost fixed excitation/emission. The decay processes of phosphor possessed a tri-exponential decay character. In the first part decay, the intensity sharply reduces to nearly $1 / 12$ th of the initial intensity within few seconds; in the second part, the afterglow emission intensity decreases slowly that persists for several minutes and in the third part, there was almost constant afterglow emission intensity. The decay behaviour of the phosphor can be fitted by an empirical equation stated as

$$
\begin{aligned}
\mathrm{I}= & \mathrm{I}_{0}+\mathrm{A}_{1} \exp \left(-\mathrm{t} / \tau_{1}\right)+\mathrm{A}_{2} \exp \left(-\mathrm{t} / \tau_{2}\right) \\
& +\mathrm{A}_{3} \exp \left(-\mathrm{t} / \tau_{3}\right),
\end{aligned}
$$

where $\mathrm{I}_{0}$ is the phosphorescence intensity at any time $t$ after switching off the excitation source, $\mathrm{A}_{1}, \mathrm{~A}_{2}$, and $\mathrm{A}_{3}$ are the weighting constants parameters, $t$ is the time period, and $\tau_{1}$, $\tau_{2}$, and $\tau_{3}$ are attenuation parameters for the exponential decay components. Using fitting functions, these parameters $\tau_{1}, \tau_{2}$, and $\tau_{3}$ can be calculated by simulating the decay curves of the phosphors. The obtained decay curves (Fig. 4(a)) in the experiment are well fitted in the above equation. Three different values of $\tau$ obtained by simulating the decay curves indicate that there are three different types of traps and hence three kinds of decay processes. The largest value of $\tau_{3}$ is related to the deepest trap centre and slowest in the decay process. Fig. 4(b) demonstrates the exponential fitting of decay profile as described in Eq. (1). The parameters generated from fitting are listed in the inset of Fig. 4(b). The exponential fitting generated parameters are $\tau_{1} \sim 39.10 \mathrm{~min}$, $\tau_{2} \sim 20.84 \mathrm{~min}$, and $\tau_{3} \sim 275.85 \mathrm{~min}$.

The afterglow duration for as-synthesized $\mathrm{E}_{3}$ phosphor is calculated as $\sim 4 \mathrm{~h}$. This longest afterglow duration possesses because its value of $\tau_{3}$ parameter is the greatest. This time is large as compared to available used fluorescent materials (e.g., $\mathrm{Y}_{2} \mathrm{O}_{3}: \mathrm{Eu}^{3+}$ ), which have lifetime in millisecond or microsecond. The large decay time is convenient to record and protect the security code and detection through naked eye for longer time due to long persistence of phosphorescence emission, which is additional advantage in such materials. The effect of dopant concentration on the afterglow properties was evaluated by varying the concentration of $\mathrm{Eu}^{2+}$ in $\mathrm{Sr}_{2.90} \mathrm{SiAl}_{4} \mathrm{O}_{11}: \mathrm{Eu}_{\mathrm{x}}{ }^{2+} / \mathrm{Dy}_{0.10-\mathrm{x}}{ }^{3+}(\mathrm{x}=0.01$ to $0.10 \mathrm{~mol}$. \%) phosphor. The decay curves of all variants of $\mathrm{Sr}_{2.90} \mathrm{SiAl}_{4} \mathrm{O}_{11}$ : $\mathrm{Eu}_{\mathrm{x}}{ }^{2+} / \mathrm{Dy}_{0.10-\mathrm{x}}{ }^{3+}(\mathrm{x}=0.01$ to $0.10 \mathrm{~mol} . \%)$ phosphor are depicted in Fig. S8 (details given in supplementary material) ${ }^{32}$ and their separately exponentially fitting curve is also shown in Fig. S9 (details given in supplementary material) ${ }^{32}$ after ceasing the $340 \mathrm{~nm}$ UV excitation source at room temperature. The Y-axis of decay curve is in log scale. The corresponding calculated weighting parameter, decay components, and decay

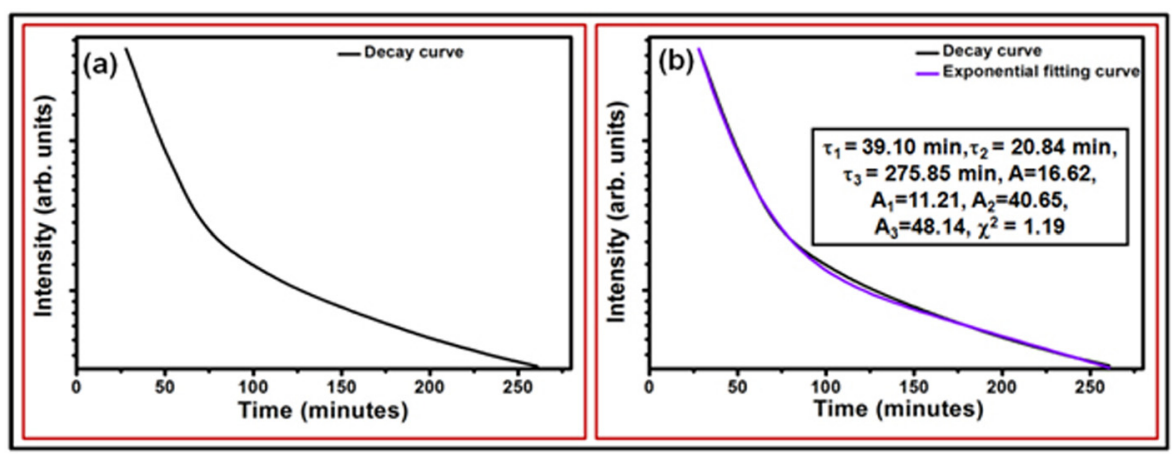

FIG. 4. (a) TRPL afterglow decay curve of $\mathrm{E}_{3}$ phosphor after ceasing the $340 \mathrm{~nm}$ UV excitation source at room temperature, it reveals a very broad time framed emission for $\sim 4 \mathrm{~h}$ and (b) the exponential fitting of decay curve and inset shows the attenuation data parameter. 
time of $\mathrm{Sr}_{2.90} \mathrm{SiAl}_{4} \mathrm{O}_{11}: \mathrm{Eu}_{\mathrm{x}}{ }^{2+} / \mathrm{Dy}_{0.10-\mathrm{x}}{ }^{3+}$ phosphor $(\mathrm{x}=0.01$ to $0.10 \mathrm{~mol} . \%$ ) are also shown in Table S II (see supplementary material). ${ }^{32}$ For all the curves, the decay time of the afterglow intensity increases first and after doping concentration $\mathrm{x}=0.03$, it decreases sharply. The $\mathrm{Eu}^{2+} / \mathrm{Dy}^{3+}$ quenching concentration begins at $\mathrm{x}=0.03 \mathrm{~mol} \%$ and the afterglow time decreases markedly from the concentration of $\mathrm{Eu}^{2+}$ exceeding $\mathrm{x}=0.03 \mathrm{~mol} . \%$. The results of the effect of $\mathrm{Eu}^{2+}$ concentration on the afterglow time of $\mathrm{Sr}_{2.90} \mathrm{SiAl}_{4} \mathrm{O}_{11}: \mathrm{Eu}_{\mathrm{x}}{ }^{2+} / \mathrm{Dy}_{0.10-\mathrm{x}}{ }^{3+}$ $(\mathrm{x}=0.01$ to $0.10 \mathrm{~mol} . \%)$ phosphor are in agreement with the conclusions obtained by Fig. S6 (details given in supplementary material). ${ }^{32}$

The long persistent decay curve is due to the deep trap energy centers of $\mathrm{Dy}^{3+}$ ions, which play a significant role in increasing the afterglow duration of phosphor material. The long decay curve of $\mathrm{E}_{3}$ phosphor was obtained under $340 \mathrm{~nm}$ excitation for $45 \mathrm{~min}$ by xenon lamp and it gives a very broad time framed emission for $\sim 4 \mathrm{~h}$. It proves its significance to explore luminescence property of such phosphors as well as its potential applications in phosphor based upcoming technology. Based on the above observations, a persistent luminescence mechanism, electron transfer model, was proposed and illustrated in Fig. 5. The mechanism of long persistence is due to the hole trapped-transported-detrapped process. ${ }^{31}$ When $\mathrm{E}_{0}$ phosphor is excited under UV light, the more number of electron-hole pairs are generated due to the presence of $\mathrm{Si}$ in host lattice, as a result band gap decreases and the direct excitation of $\mathrm{Eu}^{2+}$ due to $4 \mathrm{f}^{7} 5 \mathrm{~d}^{0}-4 \mathrm{f}^{6} 5 \mathrm{~d}^{1}$ transition occurs. A large number of holes are generated in the valance bond and some free holes moving in the valance bond are captured by $\mathrm{Dy}^{3+}$ traps, which act as a hole trap level. ${ }^{13}$ After the excitation source ceased off, the trapped holes at certain defect sites of $\mathrm{Dy}^{3+}$ are again de-trapped to the ground state of $\mathrm{Eu}^{2+}$ due to thermally stimulated recombination of trapped charge carriers at room temperature with the green emission at $510 \mathrm{~nm}$. The $\mathrm{Dy}^{3+}$ hole trap level enhances the phosphorescence by increasing the number and the depth of hole traps and it also leads to increase in the afterglow time period. Thus, it can be revealed that the re-trapping of the hole released from a trap levels plays a key role in the long persistent phosphorescence mechanism of $E_{0}$ phosphors.

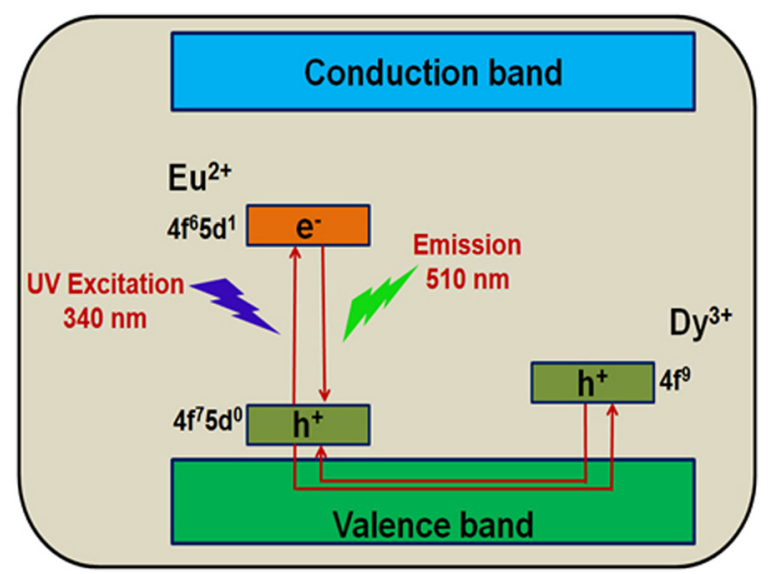

FIG. 5. Proposed luminescence mechanism of $\mathrm{E}_{0}$ green light emitting long persistent phosphor; $\mathrm{e}^{-}$denotes electron trap and $\mathrm{h}^{+}$indicates hole trap.

\section{A. Strategic applications of $\mathrm{E}_{3}$ long persistent phosphor sample}

Furthermore, the as-synthesized $\mathrm{E}_{3}$ long persistent phosphor was demonstrated for security applications in terms of latent finger-mark detection, photo-masking induced phosphorescence images, and security code detection, which is not reported earlier for this phosphor. The counterfeit money detector instrument is used for the UV excitation, as shown in Fig. 6(a). We have synthesized luminescent medium from $\mathrm{E}_{0}$ phosphor sample by dispersing the powder sample in PVC gold medium. The stability of the medium (luminescent ink) was strongly affected by the mixing process of the powder and solution. Hence, it was required that the mixing process must be performed for a longer time $(\sim 5 \mathrm{~h})$ at room temperature to produce stable colloidal solution. Fig. 6(b) demonstrates the transparency of $\mathrm{E}_{3}$ phosphor luminescent ink under room light with good stability for several hours and hyper-intense green emission peaking at $510 \mathrm{~nm}$ under excitation wavelength of $365 \mathrm{~nm}$ for $2 \mathrm{~min}$. The transmittance spectrum of $E_{3}$ phosphor is shown in Fig. S1 (see supplementary material). ${ }^{32}$ The sample is transparent $(\sim 67 \%)$ in the visible range, which contributes the formation of scattering-free luminescent film, when it is coated on black paper surface.

\section{Latent finger-mark detection}

The latent finger-marks were generated on the black paper surface under the room temperature conditions. The $\mathrm{E}_{3}$ long persistent phosphor powder mixed with PVC gold medium was then applied to the black paper surface using standard spray nosal under Ar gas pressure and the developed finger-marks were then kept in the UV exposure under excitation wavelength of $365 \mathrm{~nm}$ for $2 \mathrm{~min}$ in contrast to regular luminescent dusting powder to visualize the latent finger-marks, which can be seen in Fig. 7(a). After excitation, the UV source was ceased off and the clearly green emitting finger-marks depicts, as shown clearly in Fig. 7(b),

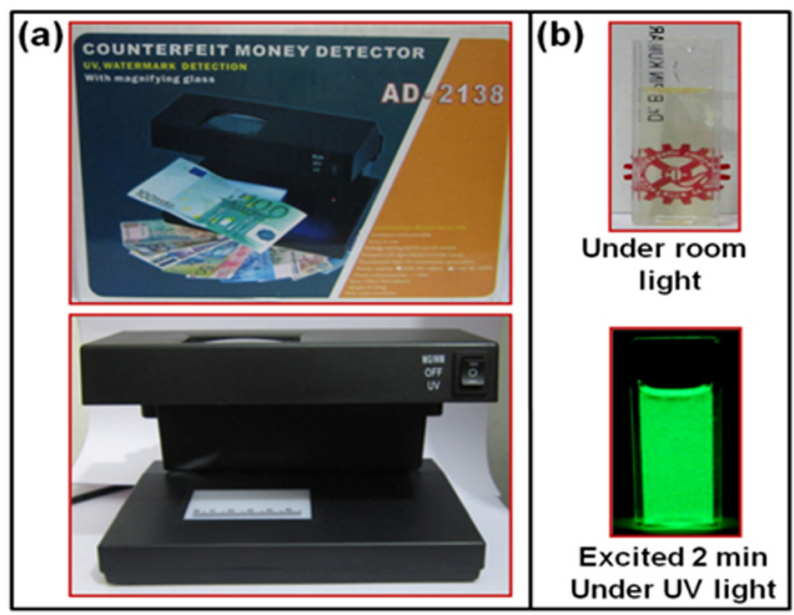

FIG. 6. (a) Instrument of counterfeit money detector which is used for the $\mathrm{UV}$ excitation at $365 \mathrm{~nm}$ wavelength and (b) the aqueous dispersion of $\mathrm{E}_{3}$ phosphor in PVC gold medium demonstrating colloidal stability and optical transparency at room temperature and highly luminescent visible (green) emission under excitation with a $365 \mathrm{~nm}$ UV source for $2 \mathrm{~min}$. 
for different time periods $(0,5$, and $15 \mathrm{~min})$. The intensity of finger-mark decreases very slowly with time. The good quality of developed finger-marks on this surface shows the greater potential of the present phosphor for the application of latent finger-marks developments. This long persistent phosphor powder developed finger-marks can be lifted by finger-marks tape and preserved in the evidence bag.

The developed finger-marks can be re-excited as many times as needed because our studies reveal that there were no obvious differences observed in the phosphorescence of the labelled finger-marks. Therefore, the above obtained results clearly indicate the application of $\mathrm{E}_{0}$ long persistent phosphor powder for spread or put on the very sensitive and bigger crime area through aerosol spraying cane. This will help to locate the finger-marks once spread and excited by the UV radiation in such areas as the long persistent $\mathrm{E}_{0}$ phosphor is up hours. Thus, the as-obtained phosphor was used as a phosphorescent labeling marker for enhanced latent finger-print detection on a variety of object surfaces in forensic science for individual identification.

\section{B. Photo-masking induced phosphorescence images}

Furthermore, we also investigated the $\mathrm{E}_{0}$ luminescent medium for photo-masking based phosphorescent images. For this investigation, the detailed systematic process is shown in Fig. 8(a). First, the images of father of the nation of India-Mahatma Gandhi, Einstein, and logo of NPL were printed on black paper to display phosphorescent images. The black paper was coated with the invisible luminescent medium of $\mathrm{E}_{3}$ phosphors. Then, the Mahatma Gandhi printed image was placed on coated black paper and exposed at UV $365 \mathrm{~nm}$ wavelength for $2 \mathrm{~min}$. After excitation, source and printed image were removed. The black paper has exhibited

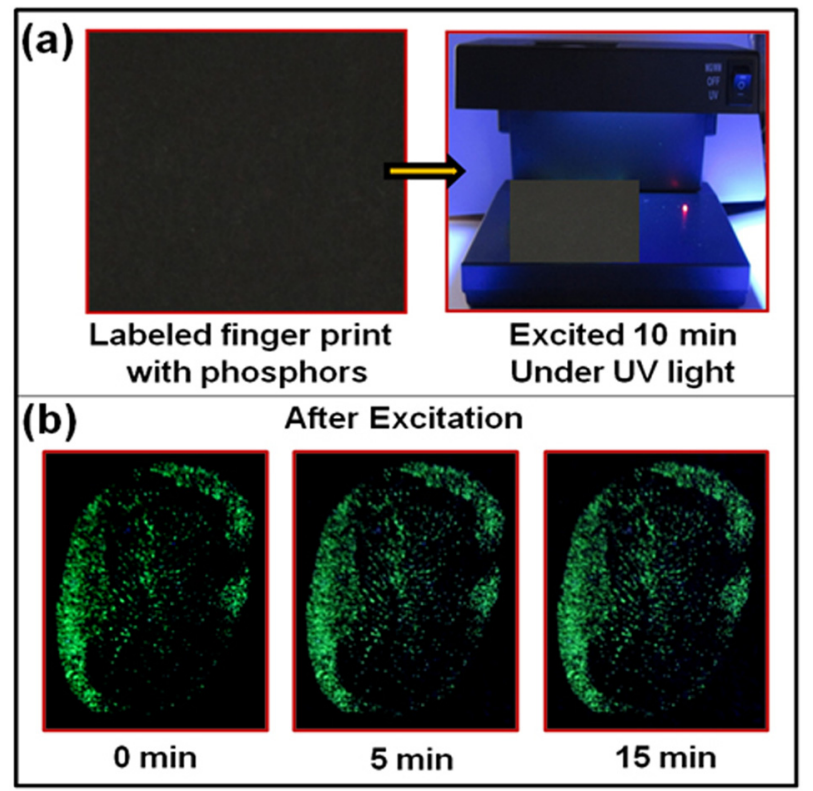

FIG. 7. (a) The labeled finger print with $\mathrm{E}_{3}$ phosphor solution on black paper surface and the developed finger-marks in the UV exposure under excitation wavelength of $365 \mathrm{~nm}$ for $2 \mathrm{~min}$ and (b) the optical images clearly depict green emitting finger-marks for different time periods (0,5, and $15 \mathrm{~min})$, when the UV source was ceased off.

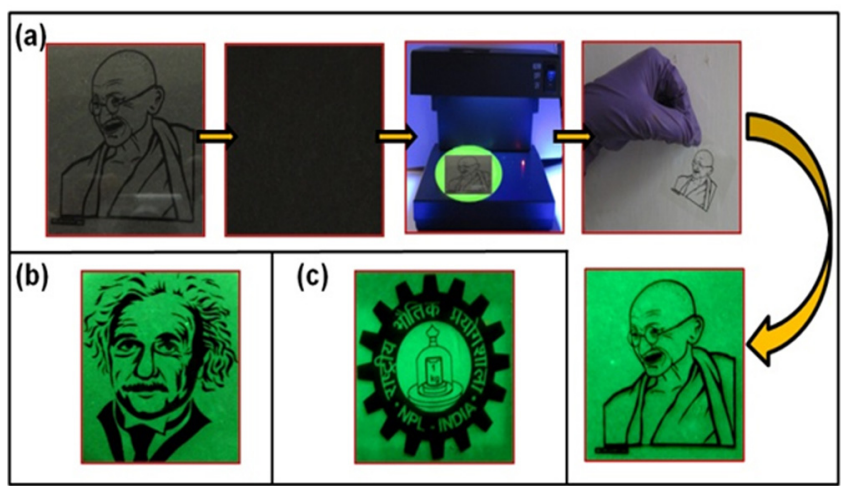

FIG. 8. (a) Photo-masking induced phosphorescent image of Mahatma Gandhi (father of Indian nation) on black paper surface exposed at $365 \mathrm{~nm}$ excitation wavelength for $2 \mathrm{~min}$; it can be noticed that it shows the strong green color emission with clear visibility, (b) phosphorescent images of eminent scientist Albert Einstein, and (c) logo of NPL, which also emits green wavelength with higher intensity.

strong green phosphorescent image, which can be easily seen on the right side of Fig. 8(a). Moreover, we also examined the same process for eminent scientist Albert Einstein and logo of NPL images. Their phosphorescent images emitting green wavelength can be seen in Figs. 8(b) and 8(c), respectively.

\section{Security code detection}

Apart from it, we also demonstrated another strategic application of luminescent medium of $\mathrm{E}_{0}$ phosphors as security code detection application. Fig. 9(a) shows the photo identity card under room temperature. The as-synthesized $\mathrm{E}_{3}$ long persistent luminescent medium sample was applied to the screen printed lotus flower on the black surface of the photo identity. The phosphor coated photo identity was then kept under the UV exposure at $365 \mathrm{~nm}$ excitation wavelength to visualize the phosphorescent lotus flower screen printed image emitting green color for security code detection, as shown in Fig. S10 (details given in supplementary mate(rial) ${ }^{32}$ and after the UV source is removed, the optical image of photo identity is taken after $5 \mathrm{~s}$, as shown in Fig. 9(b). Thus, the $\mathrm{E}_{0}$ long persistent phosphor has capability to sustain security records for few hours after the excitation source is switched off compared to available fluorescent materials (e.g., $\mathrm{Y}_{2} \mathrm{O}_{3}: \mathrm{Eu}^{3+}$ ), which have lifetime in millisecond or microsecond. Hence, this proposed phosphor provides additional advantages in terms of easy identification of code due to long persistence of phosphorescence emission for few hours as well as more energy saving. Because this is nonthermal heating process as well as emission persists for $\sim 4 \mathrm{~h}$ without continuous excitation. Additionally, the glow contrast of emission intensity can only be realized in dark as compared to day light. In day light, the ID card will be looking like almost normal if it is excited with UV lamp and switched off. It means the glow contrast will only realize in dark (for example, in box coated inside by black colour). Therefore, this phosphor is highly suitable for proposed security applications. The good quality of developed prototype shows the greater potential of the present long persistent phosphor for the security applications. Therefore, the above 


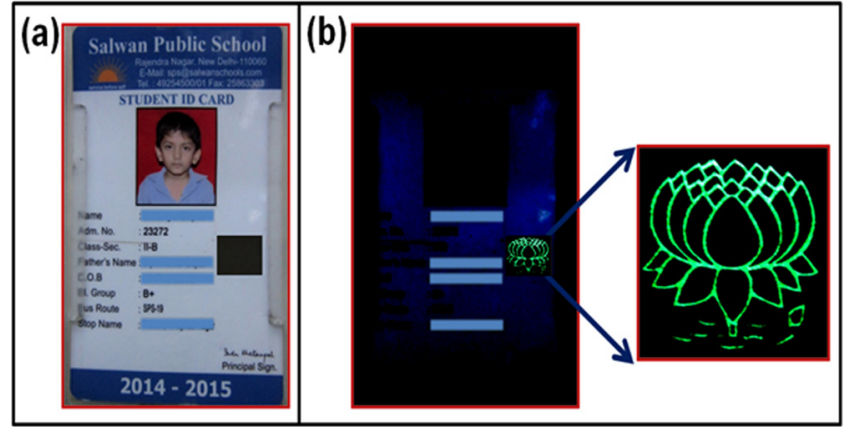

FIG. 9. The optical image of photo ID card (a) under room light and (b) after $5 \mathrm{~s}$ when the $365 \mathrm{~nm}$ wavelength UV excitation source was removed; it exhibits phosphorescent lotus flower image with emitting green color, which cannot be seen under room light, as in Fig. 9(a).

obtained results clearly indicate the application of $\mathrm{E}_{0}$ long persistent phosphor powder can be made to spread or put on the very sensitive and bigger security appliances through spraying technique as well as screen printing.

\section{CONCLUSION}

In conclusion, a novel green long persistent phosphor $\mathrm{E}_{0}$ was synthesized using conventional solid state reaction method, which can last for over $\sim 4 \mathrm{~h}$ after being excited by $340 \mathrm{~nm}$ UV light. The method of $\mathrm{E}_{0}$ phosphor synthesis is facile and it can be easily scaled up in large quantity. The PL spectra exhibit a hyper-intense maximum green emission peaking at $510 \mathrm{~nm}$ corresponding to $4 \mathrm{f}^{6} 5 \mathrm{~d}^{1}-4 \mathrm{f}^{7}$ transition of $\mathrm{Eu}^{2+}$ under UV excitation for $\mathrm{E}_{3}$ phosphor composition. During the excitation, the luminescent centre within the phosphor captures some energy and transfers it to another luminescent centre. After the excitation, the stored energy is thermally released in holes and electrons at room temperature for longer time period in green wavelength region. This is mainly due to the hole-trapped mechanism in which $\mathrm{Dy}^{3+}$ ions act as both the luminescence centers and trap-creating ions and the $\mathrm{Dy}^{3+}$ ion is responsible for the long afterglow of phosphors. Thus, the obtained highly luminescent and long persistent phosphor $\mathrm{E}_{0}$ could be an ultimate choice for security application such as in latent finger-marks detection, photo-masking induced phosphorescent images, and security code detection.

\section{ACKNOWLEDGMENTS}

The authors wish to thank Director, N.P.L., New Delhi for his keen interest in the work. The authors are thankful to Professor O. N. Srivastava (Banaras Hindu University, Varanasi) for his encouragement. The authors gratefully acknowledge University Grant Commission (UGC) and Council of Scientific and Industrial Research (CSIR), Government of India for financial assistance to carry out this work.
${ }^{1}$ G. Blasse and B. C. Grabmaier, Luminescence Materials (Springer-Verlag, Berlin, 1994).

${ }^{2}$ Y. Lin, Z. Tang, Z. Zhang, and C. W. Nan, Appl. Phys. Lett. 81, 996 (2002).

${ }^{3}$ P. Dorenbos, J. Electrochem. Soc. 152, 107 (2005).

${ }^{4}$ A. Hoppe, H. Lutz, P. Morys, W. Schnick, and A. Seilmeier, J. Phys. Chem. Solids 61, 2001 (2000).

${ }^{5}$ C. N. Xu, T. Watanabe, M. Akiyama, and X. G. Zheng, Appl. Phys. Lett. 74, 2414 (1999).

${ }^{6}$ M. Kowatari, D. Koyama, Y. Satoh, K. Iinuma, and S. Uchida, Nucl. Instrum. Methods Phys. Res., Sect. A 480, 431 (2002).

${ }^{7}$ J. Xu, Z. Ju, X. Gao, Y. An, X. Tang, and W. Liu, Inorg. Chem. 52, 13875 (2013).

${ }^{8}$ E. Nakazawa, Y. Murazaki, and S. Saito, J. Appl. Phys. 100, 113113 (2006).

${ }^{9}$ C. S. Shi, Y. B. Fu, B. Liu, G. B. Zhang, and Y. H. Chen, J. Lumin. 122, 11 (2007).

${ }^{10}$ S. R. Jansen, J. M. Migchels, T. H. Hintzen, and R. Metselaar, J. Electrochem. Soc. 146, 800 (1999).

${ }^{11}$ L. Jiang, C. K. Chang, and D. L. Mao, J. Alloys Compd. 360, 193 (2003).

${ }^{12}$ A. A. Sabbagh Alvani, F. Moztarzadeh, and A. A. Sarabi, J. Lumin. 115, 147 (2005).

${ }^{13}$ E. Nakazawa and T. Mochida, J. Lumin. 72, 236 (1997).

${ }^{14}$ K. Kaiya, N. Takahashi, T. Nakamura, T. Matsuzawa, G. M. Smith, and P. C. Riedi, J. Lumin. 87-89, 1073 (2000).

${ }^{15}$ E. R. A. Lock, W. D. Mazella, and P. Margot, J. Forensic Sci. 40, 654 (1995).

${ }^{16}$ S. H. M. Poort, W. P. Blokpoel, and G. Blasse, Chem. Mater. 7, 1547 (1995).

${ }^{17}$ L. Jiang, C. K. Chang, D. L. Mao, and B. Zhang, Mater. Lett. 58, 1825 (2004).

${ }^{18}$ Y. Ito, A. Komeno, K. Uematsu, K. Toda, and M. Sato, J. Alloys Compd. 408, 907 (2006).

${ }^{19}$ M. J. Choi, A. M. McDonagh, P. J. Maynard, R. Wuhrer, C. Lennard, and C. Roux, J. Forensic Ident. 56, 756 (2006).

${ }^{20}$ L. Liu, S. K. Gill, Y. P. Gao, L. J. Hope-Weeks, and K. H. Cheng, Forensic Sci. Int. 176, 163 (2008).

${ }^{21}$ M. J. Choi, T. Smoother, A. A. Martin, A. M. McDonagh, P. J. Maynard, C. Lennard, and C. Roux, Forensic Sci. Inter. 173, 154 (2007).

${ }^{22}$ M. Saraf, P. Kumar, G. Kedawat, J. Dwivedi, S. A. Vithayathil, N. Jaiswal, B. A. Kaipparettu, and B. K. Gupta, Inorg. Chem. 54, 2616 (2015).

${ }^{23}$ G. Kedawat, S. Srivastava, V. K. Jain, P. Kumar, V. Kataria, Y. Agrawal, B. K. Gupta, and Y. K. Vijay, ACS Appl. Mater. Interfaces 5, 4872 (2013).

${ }^{24}$ J. Dwivedi, P. Kumar, A. Kumar, Sudama, V. N. Singh, B. P. Singh, S. K. Dhawan, V. Shanker, and B. K. Gupta, RSC Adv. 4, 54936 (2014).

${ }^{25}$ B. K. Gupta, T. N. Narayanan, S. A. Vithayathil, Y. Lee, S. Koshy, A. L. M. Reddy, A. Saha, V. Shanker, V. N. Singh, B. A. Kaipparettu, A. A. Martí, and P. M. Ajayan, Small 8, 3028 (2012).

${ }^{26}$ B. K. Gupta, V. Rathee, T. N. Narayanan, P. Thanikaivelan, A. Saha, Govind, S. P. Singh, V. Shanker, A. A. Marti, and P. M. Ajayan, Small 7, 1767 (2011)

${ }^{27}$ B. K. Gupta, D. Haranath, S. Saini, V. N. Singh, and V. Shanker, Nanotechnology 21, 055607 (2010).

${ }^{28}$ B. K. Gupta, D. Haranath, S. Chawla, V. N. Singh, H. Chander, and V. Shanker, Nanotechnology 21, 225709 (2010).

${ }^{29}$ S. Chen, H. Wei, C. L. Melcher, and Y. Wu, Opt. Mater. Express 3, 2022 (2013).

${ }^{30}$ X. Lu, W. Shu, Q. Fang, Q. Yu, and X. Xiong, J. Mater. Sci. 42, 6240 (2007).

${ }^{31}$ J. Y. Zhang, Z. T. Zhang, T. M. Wang, and W. C. Hao, Mater. Lett. 57, 4315 (2002)

${ }^{32}$ See supplementary material at http://dx.doi.org/10.1063/1.4922983 for the detailed characterization technique and other related information in Figs. S1-S10, Scheme S1 and S2, and Tables S I-S II. 